\title{
Incidence and determinants of antidepressant drug use in migraine patients
}

\author{
H. Rahimtoola ${ }^{a, b}, H$. Buurma ${ }^{a}$, C.C. Tijssen ${ }^{c}$, H.G. Leufkens ${ }^{a}$ and \\ A.C.G. Egberts ${ }^{a, d}$
}

The purpose of this retrospective, follow-up study was to characterise the use of antidepressant medication in a defined migraine population and evaluate the determinants thereof. Data was obtained from the PHARMO-RLS prescription database. Our migraine population $(2,517$ people) included patients having commenced specific migraine drugs, ergotamine or sumatriptan, for the first time from January 11992 to December 31 1998. The corresponding date was termed the 'index date'. Nonmigraine patients, those not having used any medication specific for migraine, were selected and equally matched $(n=2.517)$. The cumulative incidence of initiating antidepressant treatment was estimated during two-year observation periods prior to and after the index date. Several demographic and comedication characteristics were as. sessed as potential determinants of antidepressant drug use within the migraine population. Other determinants included usage patterns ("therapeutic intensity") of ergotamine and sumatriptan, defined as the absolute number of Defined Daily Doses (DDDs) dispensed per patient during one year prior to initiation of antidepressant therapy. A total of 300 migraine patients $(11.9 \%)$ and 213 nonmigraine patients $(8.5 \%)$ had initiated antidepressant treatment in the two-year period prior to or in the two-year period after the index date (RR adj $1.4 ; 95 \% \mathrm{Cl} 1.2-1.7$ ). The cumulative incidence of initiation of antidepressant treatment for the migraine population was $3.0 \%$ per year prior to and $3.2 \%$ per year after the initiation of specific migraine anaigesia. The concomitant use of benzodiazepines (RR

\section{Introduction}

Clinical and epidemiological evidence demonstrates at clear association berween migrainc and psychiatric disorders whereby the health related quality of life of the migraineut may further be compromised (Srewart of al., 1994; Lipton of al. 2000). Current evidence has established that the life-time prevalence of major depression in migraine, for example, is about rhree rimes highct (34\%) than thar estimated in the non-migraine population $(10 \%)$ and that the prevalence of anxiety or panic disorders aftects approximately $11 \%$ of the migraine popularion compared to $2 \%$ of the non-migraine population (Breslau $d$ al, 2000; Brestau $e$ al, 1991). The risk for psychiatric comorbidity seems to be strongest in women, migraincurs suffering from the aura symptoms or those adj $4.7 ; 95 \% \mathrm{Cl} 3.5-6.3)$, migraine prophylactic medication (RR adj 2.1;95\% $\mathrm{Cl} 1.6-2.8$ ) and heavy therapeutic intensity use of specific migraine analgesia, defined as $\geq 150$ DDDs per year were highly predictive of antidepressant drug use within the migraine population.

In conclusion, compared to the non-migraine population, the initiation of antidepressant treatment was only slightly higher in the migraine population. A number of determinants within the latter were found to be strongly associated with antidepressant drug use, the nature of which most likely reflects an increased severity of migraine whereby therapeutic needs are higher. Int Clin Psychopharmacol 18:331-339 \& 2003 Lippincott Williams \& Wilkins.

International Clinical Psychopharmacology 2003, 18:331-339

Keywords: ergotamine, sumatriptan, migraine, antidepressant, therapeutic intensity

"Department, of Pmarmacoep demiosogy and Phamntotherapy. Utrecht Institute for Pharmaceutical Sciences (UIPS), Utrecht, The Netherlands, "SIR institute for Pharmacy Practice Resweirch, Leideo, The Nethertands. "Deparment of Neurology, St Elisaboth Hospital, Tilburg. The Nothorlands and 'Hospital Pharmacy Micider Brabant. Twee Steden Hoxpital and St. Elsabeth. Hospital, Tilburg. The Netherlands

Corresponderice and tequesto for reprints to Dr Hamid Rahimtoola, Apotheek de Notekraket, Wimkanplein 1, 1311 LH. Almere. The Nothertands. Tel: +31 36 5461850, foc + 31365461855 ; e-mal: aponotekrakerigzorggroeo-ialmerc hi

Received 10 December 2002 Accepted 4 Septembor 2003

with transformed migenine (Breslau of al., 2000: Breslau at d., 1991; Swartz of d., 2000; Juang of ah, 2000 ).

It still remains unclear whether psychiartic comorbidity is primarily related to a unidirectional (cause or effect) psychological component or a bidirectional process (common environmental genetic etiology). By studving psychiatric comorbidity in migraine patients, Breslau of af. (2000; 1991) demonstrated a strong bidirectional telaronship between major depression and migraine, meaning that migraine predicted first-onset depression and depression predicted first onser migraine (Breslau a $a /$. 2000: Breslau et al, 1991: Breslau, 1998: Peroutka er d., 1998). However, orher studies could not support the shared mechanism hypothesis berween migraine and 
psychiatric comorbidity or whether in fact an association between these two disorders exits (Swartz of al., 2000): Merikangas at al. 1990; Guillemn ot al, 1999; Mattsson et $a l, 2002)$.

Although a clear association between migraine and major depression may exist, the phenometion appears to be under recognised and under treared in elinical pracrice (Devlen, 1994). To what extent is unclear since only a few epidemiological studies have provided data concerning the patterns of antidepressant drug use in migraineurs suffering from coexisring psychiatric disorders. Putnam at al. (1999) by studying comedication characteristics in patients using sumatriptan estimared that antidepressants were used by approximarely a third of the study patients. A recent study concerning the incidence and determinants of migraine prophylacric medication had shown that use of antidepressants and/or benzodiazepines was associated with an increased initiation of migraine prophylactic medication, possibly due to underlying psychiarric illness complicating migraine treatment (Rahimtoola of al., 2002).

The question therefore arises as to whether the use of antidepressants by migraineurs is primarily a cause or consequence of onser of specific migraine drug treatment. The purpose of this study was to investigate the nature of the association between antidepressant and specific migraine analgesic drug use by estimating the incidence of initiation of antidepressants prior to and afeer the initiation of specific migrainc analgesics. Furthermore a number of characteristics were explored within the migraine population in order to identify any potential determinanes associated with the initiation of antidepressant medication.

\section{Methods \\ Study setting}

The study used preseription data from the PHARMORI.S database covering the period 1985 to 1999 . This database has been described in full by Herings $a$ al. (1992). This darabase system provides relevant demographic and prescription data on an individual pariene level for 8 medium sized cities ( $n=450,000$ inhabitants) in The Nerherlands, In view of a high patient-pharmacy registration commitment in The Netherlands in addition to sophisticated pharmacy software currently awailable. the medication information for each primary care patient is virtually complete. Each registered person is identified with an anonymous unique patient identification code that allows for the observation of patiene medication use in time. Retrievable information per prescribed medicine includes date of dispensing, drug, dosage regimen, quantity supplied (Defined Daily Doses), duration of use and rype of prescriber. Patient information per preseribed medicine includes gender, and dare of birth.
The database does not provide information concerning the indications for use of the medicines, in this case the diagnosis of migraine versus cluster or tension type headaches, or the complete registration of non-prescription medicines (c.g. OTC use of salicylates, NSAIDs or paracetamol), as patients may also purchase these drugs from non-pharmacy outlets.

\section{Study population}

As diagnostic and clinical dati were lacking we were required to identify the migraine popularion by the use of specific abortive migraine drugs, including ergotamine and sumatriptan. Analysis of the data can only be valid for this particular population in whom a more severe form of headache, compared to other migraineurs who do not require these drugs, may exist. For this recrospective, follow-up study, patients having commenced a specific migraine drug, either etgotamine or sumatriptan, for the first time from January 11992 to December 311999. were initially identified. First time users were defined as patients possessing a drug free interval of abortive migraine drug use of ac least two years. The date of first prescription of one of these drugs was termed the index date'. Patients were only included if they had presented more than one prescription during follow-up, as recent data suggest that one time use of one of these drugs is a partial indication of an uncertain diagnosis for migraine (Rahimtoola ef al, 2003). Furthermore, each patient was required to have possessed at least fous years of prescription data, equivalent to two years before and after the index date. For this reason patients using one of the second generation triptins were not included. For each ergoramine or sumatriptan patient, one reference patient not having used migraine specific medication (i.e. ergotamine, triptans, pizotifen, flunarizine, clonidine, and methysergide) werc randomly selected from eligible nonmigraine patients from the PHARMO database and were matched on age, sex, Jocality, and index date $( \pm 90$ days $)$. For the purpose of this study reference patients were referred to as non-migraine parients.

\section{Outcome definition}

The primary outcome of interest was the initiation of antidepressant drug treatment. Each eligible patient was therefore screened for the first rime use of an antidepressant during the two-year follow-up periods prior to or after the index date. First time use was defined as an antidepressant drug frec interval of at least one year prior to commencing one of the corresponding drugs. The corresponding date was termed antidepressant start date', Antidepressants included tricyclic antidepressants (TCAs-excluding amitryptiline), selective serotonin reuptake inhibitors (SSRIs), monoamine oxidase inhibitors (MAOIs), and other non TCAs (trazadone, nafazodone, mianserine, mirtazipine and venlafaxine). Amitriptyline was not included as this drug was recommended in the 
migraine prophylactic therapeutic guidelines for primary care physicians during the study period. Fven though some SSRIs, such as fluoxerine and fluvoxamine, ot MAOls, such as moclobemide and quite recently nafazodone, have shown to display useful effects in migraine prevention, they were still included in our inalysis as they were not included in international therapeutic guidelines for migraine prevention during the study period (Silberseein and Goadsby, 2002),

\section{Data analysis and potential confounders}

The cumulative incidence (cumulative incidence per year) of iniriating antidepressant rreatment by migraineurs and non-migraineurs during the two-ycar follow-up periods prior to and after the index dates were estimated per six-monthly interval. The incidence within the migraine population was also compared during the twoyear follow-up periods prior to and after the initiation of specific abortive migraine theraps. Baseline characteristics of the study migrane $(n=2,517)$ and non-migraine population $(\mu=2,517)$ were examined and included gender, age, and "comorbidiry index". The presence of coexisting chronic conditions has shown to lead to at higher occurrence of depressive disorders and corresponding antidepressant drug use in the general population. Since migraine patients are substantially more likels than non-migraine patients to be diagnosed with a variety of comorbid condition(s) we included the comorbidity index in order to adjust for the porential burden of coexisring illness as a potential confounder for the risk of antidepressant treatment (Joish of al, 2000). The latter was derived from a chronic disease seore estimated for each parient by assigning scores $(0-5)$ to specific classes of drugs according to the severity of the disease for which they were prescribed during the total observation period (Korff et al, 1992). The latter included drugs used for cardiovascular, respiratory disorders, rheumatoid arthritis. chemotherapy, Parkinson's disease, epilepsy, diabetes mellitus, gastrointestinal uleer, gout, hypercholesterolemia, and glaucoma. In order to adjust for an increased exposure to prescription medication within the migraine population due to a possible increase in physician consultation after having initiated ergotamine or sumatriptan, we estimared the total number of prescriptions dispensed per six-monthly interval during each two year observation period as an estimation of potential patientphysician contact. Both comorbidity index and parientphysician contact estimate in addition to the rype of prescriber of the first ancidepressant prescription were analysed as differential factors for the use of antidepressant drugs in the two populations.

The second approach to our srudy was to identify ans potential determinants predictive of the initiation of an antidepressant within the migraine population for which several patient and medication related characteristics were analysed. These included age and gender, rype of abortive migraine medication used, co-medication used during the total observation period, comorbidity index and prescription exposure index. Comedication included cardiovascular drugs (ACE inhibitors, calcium channel antagonists, $\beta$-adrenergic blockers-cxcluding propranolol and metoprolol, nitrates, digoxin, diuretics, vitamin-K antagonists, HMG (OOA reductase inhibitors), diatseres, benzodiazepines, gastrointestinal agents (proton pump inhibitors, $\mathrm{H}_{2}$ antagonists), migraine prophylactic drugs (propranolol, metoprolol, pizotifen, flumarizine, clonidine, methysergide, and amitriptyline). NSAIDs, and oral contraceptives.

A level of severity of migraine was likewise analysed as a potential determinant and was indirectly correlated to the consumption and switch patterns (change from crgotamine to sumatript and visa versa) of abortive migraine analgesia, Consumption patterns ("rhetapeutic intensiry") were cstimated by calculating the absolute consumption of ergotamine and sumatriptan based upon the sum of DDDs of ergotamine and sumatriptan dispensed during a one-year observation period prior to the antidepressant statt date. Therefore, this particulat analysis included only those patients who had commenced ancidepressant treatment after having intiated ergotamine or sumatriptan (index group) and the reference group included those patients who had not. The latter were matched with the index group by a prescription date that corresponded to the antidepressant start dare of the cases, $( \pm 90$ days). Patients were subsequently categorised according to $<30$, $\geq 30-<$ 90 , $\geq 90-<150$, and $\geq 150$ DDDDs. Even though an established definition for excessive use of specific aborrive migraine analgesics is lacking we defined this as the use exceeding $150 \mathrm{DDD}$ )s or more. which has also been applied in other drug utilization studies involving sumatriptan and ergotamine (Evers of af, 1999; Gaist, 1999). The following provides the DDDs of ergotamine and sumarriptan recommended by the World Health Organization (WHO, 1993):

1 DDD sumatriptan corresponded to one $100 \mathrm{mg}$ tablet, one $6 \mathrm{mg}$ subcutaneous injection or one $20 \mathrm{mg}$ nasal spray

I DIDD ergotamine corresponded to one $4 \mathrm{mg}$ single preparation by any route of one $2 \mathrm{mg}$ combination prepuration by any roure.

In order to rest the strength of the association between the various determinants studied and the initiation of antidepressant treatment berween the migraine and non-migraine populations, logistic analysis was applied (adjustments for age, gender, type of aborrive migraine drug used and comorbidity index). Odás ratios were used 
Table 1 Baseline characteristics of the study population (migraine and non-migraine patients)

\begin{tabular}{|c|c|c|}
\hline Characteristic & $\begin{array}{c}\text { Migraine } \\
N=2.517(\cos )\end{array}$ & $\begin{array}{l}\text { Nonimigraine } \\
N=2,517 \text { (Fib) }\end{array}$ \\
\hline \multicolumn{3}{|l|}{ Gender: } \\
\hline Female & $2.089\langle 83.0\rangle$ & $2,086(82.9)$ \\
\hline Maie & $428(170)$ & $43:(17.1)$ \\
\hline \multicolumn{3}{|l|}{ Age } \\
\hline Mean (SD) in yoars & $44.5(12.6)$ & $44.6(12.8)$ \\
\hline$<25$ & $156\{6.2\}$ & $156(6.2)$ \\
\hline $25-44$ & $1092(43,4)$ & $1110(44.1)$ \\
\hline $45-64$ & $1106[43.9)$ & $1080(42.9)$ \\
\hline$>64$ & $163(6.5)$ & $171(6.8)$ \\
\hline \multicolumn{3}{|l|}{ Chronic distease seore } \\
\hline 0 & $1,265\{50.3\}$ & $1949(53.6)$ \\
\hline$<2$ & $561(26.3)$ & $746(29.6)$ \\
\hline$\geq 2$ & $591(23.5)$ & $422\{16.8\}$ \\
\hline \multicolumn{3}{|l|}{ Coniedication } \\
\hline Asthma/COPD & $296(11 B)$ & $318(12.6)$ \\
\hline Benzodiazepines: & $1,126(44.7)$ & $885(35.2)$ \\
\hline Cardicovascular & $579(230)$ & $581(23.1)$ \\
\hline Diabetes & $123(4.9)$ & $145\langle 5.8\rangle$ \\
\hline Esilepsy & $102\{4,1\}$ & b7 $\{2,7\}$ \\
\hline Gastrointestinal & $418(16.6)$ & $322(12.8)$ \\
\hline Antidepressant use" & $348(13,8)$ & $247(9.8)$ \\
\hline \multicolumn{3}{|c|}{ Physician contact estimate } \\
\hline \multicolumn{3}{|c|}{ Mean (seny) RxE presented: } \\
\hline Prior andex cate & $80\{0.3\rangle$ & $83(0.2)$ \\
\hline After index date & $8.9(0,3)$ & $9.4(0.2)$ \\
\hline
\end{tabular}

"urespective of firat time use

to express the strength of the associations and were interpreted as relative risks (RR $95 \% \mathrm{Cl}$ ).

Microsoft Access, a relational dacabase software package. was used for database management and internal qualicy and validation procedures. The statistical package, SPSS for Windows (version 10.0) was used for data analysis (Table 1).

\section{Results}

After fulfilling eligibilty eriteria, a total of 2,517 parients. had commeneed either ergotamine or sumatriptan for the first time after 1992. Natching criteria identified 2,517 patients as the reference group. The majority of the study population included females $(82.9 \%)$ and the mean age was 44.6 years $(S I): 12.7)$.

A total of 513 patienes $(10.2 \%)$ of the total study population had been prescribed an antidepressant drug for the first time during the four-year observation period. This corresponded to an average cumulative incidence of $2.7 \%$ per year. Antidepressant drug use was observed in 348 and 247 migraine and noh-migraine patienss. respecrively, of whom a total of 82 were excluded from further analysis as they were considered non first time users. A total of 300 migraine parients (11.9\%) had iniriated antidepressant treatment prior to or after the index date as opposed to 21.3 reference patients $(8.5 \%)$, (RR adj 1.4: 95\% (.I 1.2-1.7), (Figure 1 and Table 2).
Fig. 1

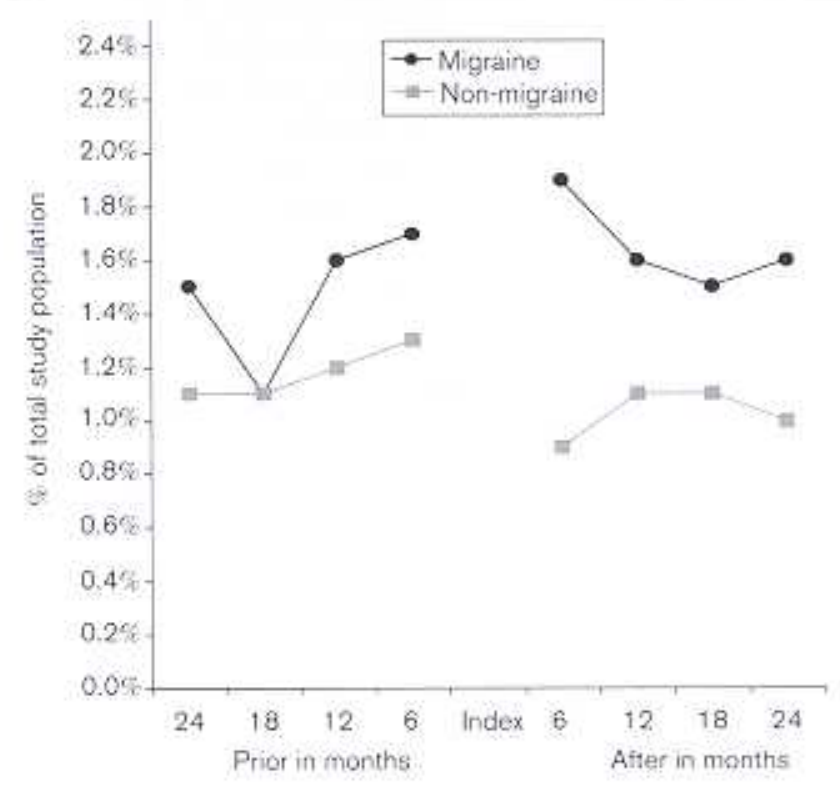

Incidence of intiation of antidepressant drugs prior to and after index date.

There were no striking fluctuations in the initiation of antidepressant treatment prior $(5.8 \%)$ or after $(6.2 \%)$ the iniriation of ergotamine or sumatriptan. This incidence pattern was similarly observed for the non-migraine population. Notably, for the migraine patients the cumulative incidenee per six-monthly interval had reached its highest level shortly prior to $(1.7 \%)$ and after (1.8\%) the index date. respectively For the reference group, the incidence remained consistent throughout the observation period at $1.1 \%$, tor which minimal flucruarion during the six monthly intervals, prior to and after the index dates, was found.

Although, the initiation of antidepressive treatment was predominantly prescribed by general practitioners for all patients (Table 2), a weaker involvement by neurologists compared to general practitioners was observed in migaine patients (RR adj $0.6 ; 95 \%$ Cl 0.4-0.9). Furthermore migraineurs having started antideptessant therapy demonstrated a stronger comorbidity index, as defined by the chronic disease score of $>2$. compared to non-migraine parients (RR adj 2.7: 95\% CI 1.7-4.2). There were no large differences observed between both groups in terms of gender, age or physician contact (or prescriprion exposure). A weaker preference for an SSRI as a first line antidepressant, however, was in fact observed for the migraine population (RR adj $0.5 ; 95 \%$ (.I $0.3-0.7$ ).

Table 3 displays the strength of the association between various determinants examined and initiation of anti- 
Table 2 Determinants of initiation of antidepressant medication for migraine versus non migraine patients

\begin{tabular}{|c|c|c|c|c|}
\hline & Migraine N 156$)$ & Non-rnigraine $N(\% 6)$ & RR otude [s\$o Cl] & $\mathrm{RR}$ adj $195 \% 6 \mathrm{Cl}]$ \\
\hline Orerall & $300(12.2)$ & $213(8.6)$ & $1.5 .\{1.2-1.8\}$ & $1.4[1.2-1.7]$ \\
\hline \multicolumn{5}{|l|}{$\begin{array}{l}\text { Peniod of initiation } \\
\text { Phor }\end{array}$} \\
\hline Prior & $145\{5.9\}$ & $115(4.6)$ & 1.0 Irefentencel & 1.0 Ireterencel \\
\hline Post & $155\{6,3\}$ & 98 (3.9) & $13[0.9-1.8]$ & $1.3 \mid 0.9-1.8)$ \\
\hline \multicolumn{5}{|l|}{ Type of antideoressant } \\
\hline TCA & $195(65.0)$ & $97\{45.5\}$ & 1:0 Ireterencel & 10 [roference) \\
\hline SSRI & $94\{91.3\rangle$ & $102\{47,9\}$ & $0.5 \mid 0.3-0.7\}^{\prime}$ & $0.5[0.3-0.7]$ \\
\hline MAC4 & $2(0.7)$ & $2(0.9)$ & $0.5[0.1-3.6]$ & $0.5[0.1-3.4]$ \\
\hline Other & $9\{3,0\}$ & $12(\$ .6)$ & $0.4 \mid 0.2-0.9\}$ & $0.3[0.1-0.8]$ \\
\hline \multicolumn{5}{|l|}{ Prescriber } \\
\hline Geneiral practitaner & $242\langle 80.7\rangle$ & $15,4(72,3)$ & 10 [reference] & 1.0 Ireterencel \\
\hline Specialist & $58(193)$ & $59(27.7)$ & $0.6[0.4-0.9]$ & $0.6[0.4-0.9]$ \\
\hline \multicolumn{5}{|l|}{ Comorbinily inder } \\
\hline 0 & $106(35.3)$ & $112(52$ B) & 1.0 lreierencel & 1.0 [refierence] \\
\hline$\leq 2$ & $89(29.7)$ & $60(28.2)$ & $1.6[1,0-2.41$ & $16[1.0-2.4]$ \\
\hline$>2$ & $105(35.0)$ & $41\langle 19.2\rangle$ & $2.7 \mid 1,7-4.2\}$ & $2.7[1.7-4.2]$ \\
\hline \multicolumn{5}{|l|}{ Physician contact } \\
\hline \multicolumn{5}{|l|}{ Rx exposuté } \\
\hline$\leq 3$ & 17 (5.7) & $15\{7,0\}$ & 1.0 Itefercucel & 1.0. [reference] \\
\hline$>3.6$ & $51(12.0)$ & $48|22,5|$ & $0.9[0.4-2.1]$ & $10(0.4-2.2)$ \\
\hline$>6-9$ & $61\{20.3\}$ & $42(197)$ & $1.3[0.6-2.8]$ & $1.4[0.6-2.6]$ \\
\hline$>9$ & $17+(570)$ & $108\{50.7\}$ & $1.4|0.7-2.9|$ & $1.2|1.1-1.3|$ \\
\hline
\end{tabular}

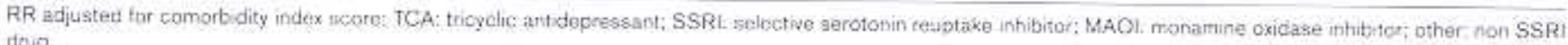
drug.

depressants only within our migraine popularion. Female gender (RR adj $1.3 ; 95 \%$ C.I $1.1-1.7$ ) and the use of gastrointestinal drugs (RR udj $1.6 ; 95 \%$ C. $1.2-2.3$ ) were found to be weakly associated with the initiation of antidepressant drug trearment after adjusting for age, gender. type of abottive migraine drug and comorbidicy index score. The concomitant use of benzodiazepines (RR adj $+.7 ; 95 \%$ CI $3.5-6.3$ ), migraine prophylacric drugs (RR adj 2.1: 95\% Cl 1.6-2.8) and NSAII)s (RR adj 1.8: $95 \%$ CI $1.4-2.3)$ was considerably higher in parients having initiated an antidepressant. This was further highlighted by an increased comorbidiry index score $>2$ (RR adj $2.5 ; 95 \%$ CI $1.8-3.3$ ). An assessment of severicy of migraine as a potential determinant for the initiation of antidepressant therapy was indirectly estimated by the consumption (therapcuric intensity) and switch parterns of ergoramine and sumatriptan displaved during a one year period prior to initiating antidepressant therapy, Heavy use of ergotamine and sumatriptan, defined by a therapeuric intensity of $\geq 150$ DDDS, was more pronounced in the index group than in the reference group (RR adj $3.4 \div 95 \% \mathrm{Cll} 1.4-8.5$ ) as well as an increased rendency to switch treatment from ergotamine to sumatriptan or visa versa during this period (RR adjusted 2.5: 95\% CI $1.6-4.0)$.

\section{Discussion}

The iniriarion of antidepressants within our migraine parient population was only slightly higher to that found in the reference group, $12 \%$ compared to $9 \%$. Characteristics most clearly and independently associated with the use of antidepressants within the migraine population were the high burden of comorbidics, concomitane use of benzodiazepines, migraine prophylactic medication. NSAIDs, and heavy as well as swirching use of specific migraine analgesia.

The prescribing of (migraine and non-migraine) antidepressant treatment for the total study population was approximately $3 \%$ per year and similat to data obtained from other European studies is considered low (Rouillon et al. 1996; Bellaneuono of al. 2002). Rouillon et al. (1996) determined that $2.75 \%$ of their study population had been prescribed antidepressant therapy, far lower to the actual prevalence estimated for depression in the general population which is about $10 \%$. Possible reasons for under trearment of the population suffering from depressive disorders may be the underreporting of related symptoms to physicians and general problems wirh access to medical care (Druss $x$ ul., 2000),

A number of cross-sectional and longitudinal studies have estimated that the liferime prevalence of major depression in migraineurs may range from $30 \%$ to $40 \%$ (Breslau of al. 2000; Juang ef al, 2000; Breslau, 1998; Martsson and Ekeslius, 2002; Fasmer. 2001). The incidence of antidepressant drug use, as in indicarion of co-existing depression, in our study is, therefore, far Jower. Data from 
Table 3 Determinants of antidepressant drug use within ergotamine and sumatriptan patients

\begin{tabular}{|c|c|c|c|c|}
\hline \multirow[t]{2}{*}{ Detemminant } & \multicolumn{2}{|c|}{ Initation of antidepressant medication } & \multirow[t]{2}{*}{ OR $[95 \% \mathrm{CH}]$} & \multirow[t]{2}{*}{ OR adj l95: Cl] } \\
\hline & Yes $n=300(0))$ & No $n=2,169(9)$ & & \\
\hline \multicolumn{5}{|l|}{ Gendet: } \\
\hline Male & $43(1.4 .3)$ & $380(17.5)$ & 1.0 |reterence] & 1,0 freterenco\} \\
\hline Female & $257\{85.7\}$ & $1789(82.4)$ & $13[0.9-1.8]$ & $1.3|1.1-1.9|$ \\
\hline Mean age (SD) in years: & $45.1(12.5)$ & $44.3(12.3)$ & & \\
\hline$<46$ ytars & $152\{50.6\}$ & $1081(49.8)$ & 1.0 [reterence] & t.0 [reterence] \\
\hline 245 years & $148(49.3)$ & $1.088(50.2)$ & $1.0[0.8-1: 2]$ & $0.9[0.7-11]$ \\
\hline \multicolumn{5}{|l|}{ Jype of migrane analges!a: } \\
\hline Engotamine & $218(72.7)$ & $1680(725)$ & 1.0 [reference] & 1.0 beferencel \\
\hline Sumatrptan & $82(27,3)$ & $489\{22.5\}$ & $1.3[1.0-1.7]$ & 1,3 [5:0-1 日] \\
\hline \multicolumn{5}{|l|}{ Compdication } \\
\hline Catc sovasceulut & $21\{2.0\}$ & $172(7,9)$ & $0,9[0,5-1,4]$ & $1.2\{07-20\}$ \\
\hline Benzadfazepines & $234(78.0)$ & $892\{41.1\}$ & $5.1[3.8-6.8]$ & $4.7[3.5-6.3]$ \\
\hline Diabetes & $13(4: 3)$ & $68(3,1)$ & $1.4[0.8-2.6]$ & $1.40 .8-2.6]$ \\
\hline Gastrointestinal & $47(15.7\}$ & $222\langle 102\}$ & $1.6[1.2-2.3]$ & $1.6[1.2-2.3]$ \\
\hline Migraine prophyiaxis: & $104\langle 34.7\rangle$ & $423\langle 195\rangle$ & $2.2[1.7-2.8]$ & $2.1[1.6-2.8]$ \\
\hline NSAID: & $191(63.7)$ & $1060\{4 \theta .9)$ & $1.8\{1.4-2.4\}$ & $1.8(1.4-2.3)$ \\
\hline Oral coctraception & $151(50.3)$ & $974(44,9)$ & $1.2\{1.0-1.6\}$ & $13(1,0-1,8)$ \\
\hline \multicolumn{5}{|l|}{ Comorbidiny indor } \\
\hline 0 & $106(35.3)$ & $1149\{530\}$ & 1.0 treference! & 1.0 [reference] \\
\hline $1-2$ & $89(29,7)$ & $553(25.5)$ & $1.7|1.3-2.4|$ & $1.7\{1.3-2.4\}$ \\
\hline$>2$ & $105(350)$ & $467\{215\}$ & $2.4[1.8-3.3]$ & $2.5\{1.8-3.3\}$ \\
\hline \multicolumn{5}{|l|}{ Physician comact } \\
\hline \multicolumn{5}{|l|}{ Rx exposure } \\
\hline$\leq 3$ & $17\{5.7\}$ & $518: 23.91$ & 1.0 |referencel & 1.0 [roterence] \\
\hline $3-6$ & $51(17.0)$ & 745134.3 & $2.1|1,2-3,7|$ & $2.1\{1.2-3.6\}$ \\
\hline $6-9$ & $61(20.3)$ & $417(19.2)$ & $4.5[2.6-7.7]$ & $4.6\{2.6-8.0\}$ \\
\hline$>9$ & $171,\{57.01$ & $489(22,5)$ & $10.7[6.4-17.8\}$ & $71,4[6,8-19,2]$ \\
\hline \multicolumn{5}{|l|}{ Therapeutic intensity } \\
\hline Mean ODDs $\mid$ sem $\left.\right|^{*}$ & $28.1\langle 2.71$ & 19310.81 & & \\
\hline$<30$ & $121\langle 78.1\rangle$ & $1554(B 1,0)$ & 1.0 keterencel & 1.0 lreterencel \\
\hline $30-<90$ & $20\langle 12.9\}$ & $286(1.4 .9)$ & $0.9|0.6-1.5|$ & $0.9[0.5-1.5]$ \\
\hline $90-<150$ & $7(4.5)$ & $56(2.9)$ & $1.6[0.7-3.6]$ & $1.6[0.7-3.6]$ \\
\hline 150 & $7\{4,51$ & $23(1.2)$ & $3.8(1.5-9.3)$ & $3.4[1.4-8.5]$ \\
\hline Swich use & $28\{18,1\}$ & $115\{(7,3\}$ & $2.8[1,8-4,4]$ & $25[1.6-4.0]$ \\
\hline
\end{tabular}

OR ad,uted for age, gender, type of abortive migraine anajgesu. pomorbidity inder score.

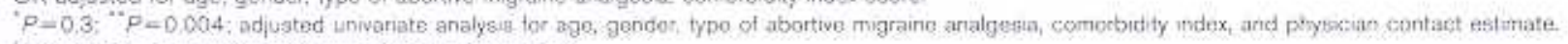

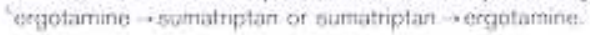

the same studies have shown that migraineurs have a two or three fold increase in the risk of major depression (Breslau it al. 2000; Swartz a d. 2000; Merikangas a al. 1990). However, contrary to our a priori expectations, the relarive risk of ancidepressant drug use in our migraine population compared to the non-migraine population was estimated at 1.4, far lower to that seen in these studies. Finally, Nillson et af. (2000) found that that between 1993 and $199723 \%$ of all triptan parients studied were diagnosed by a general practitioner with depression and was found to be significantly higher to that observed in non-triptan parients $(16.8 \%)$. According to this study, this is most likely attributed to an increasing consultation with the physician due to an increasing severity of migraine. Of the ergotamine and sumatriptan patients in our study an estimated $12 \%$ had initiared antidepressant treatment during the observation period (eirher prior to or after the initiation of ergotamine or sumatriptan), far fower than those who had been diagnosed and treated with depression in the former study. This available dara suggests a relative under treatment of depression in patients suffering from migraine within our study area, for which various underlying reasons are plausible.

Firstly, the use of antidepressants offers only one of the available treatments for depression. For example, cognitive behaviour therapy or orher psychotherapies can be as effective for specific individuals, either alone or in conjunerion with medication. Furthermore, our migraine population was restricted to those patients who had been using specific abortive migraine drugs. A few drug utilization studies conducted in the migraine population have consistently found that the prescribing of these drugs is low (Edmeads ot al. 1993; Furlong of al., 1996). von Korff at al. (1999) found that only $17 \%$ of a group of primary eare migraine patients were using these drugs 
and that the majority were using OTC and/or non-specific prescription analgesics. Our migraine population ean therefore only represent a portion of the overall migraine population, whereby the prevalence of depressive comorbidity compared to the general population may be underestimated.

The relatively high level of under consultation frequently abserved within the migraine population may lead to under diagnosis and under treatment for migraine itself as well as potential neurological disorders and can be considered an alternative explanation (Furlong of al., 1996). Recognition and treament of psychiatric comorbidicy in migrainc patients, as noted within the general population, should be emphasised as the quality of life of many migraineurs can be further compromised in the presence of comorbid psychiatric illnesses (Lipton $a d$. 2000).

The presence of coexisting migraine and depression will certainly provide the prescriber opportuniries but also limitations for treatment. Preliminary lindings have demonstrated that some ancidepressants, such as flwoxetine, nefazodone, and moclobemide have shown promising results in the preventive treatment of migraine and chronic daily headaches (Silberstcin and Goadsby, 2002). They may, therefore. allow the physician to effecrively treat both migraine and depression. However, the combination of an SSRI or MAOI with sumatriptan are not devoid of serious side-effects, such as the serotonin syndrome, and as such should be used with caution when indicated (Putnam ot al., 1999: Joffe and Sokolov, 1997), Evidence of adherence to this precautionary measure can distinctly be observed in our study as the prescribing of a TCA was clearly preferred to an SSRI as a first line antidepressint in the majority of our ergotamine and sumatriptan treated patients. Nevertheless, since the SSRIs are the most commonly prescribed of antidepressants, the prescribing of these drugs to a migraincur using sumatriptan will be unavoidable, as we had observed in approximately one third of treated migraineurs (Rouillon at al, 1996).

Variations in the incidence of antidepressane use prior to and after the iniriation of specific abortive doug trearment could not be found, suggesring that the risk of initiation of treatment of the two condicions is bi-direcrional (i.e. trearment of each disorder increases the risk of treating the other). This is furrher supported by our findings that a gradual increase in the initiation of psychotropic drug use was observed shortly prior to as well as after the initiation of ergotamine and sumatriptan. However, due to the lack of elinical data, we cannot claim whether the assneiation between the onset of migraine and psychiatric comorbidity is bi-directional, as confirmed in other studies (Breslau et $d /$. 2000; Breslau ot al. 1991: Breslau,
1998), as the initiation of specific abortive migraine treatment cannot be considered an indication of the inicial diagnosis of migraine for a patient, but more likely an indication of an increasing severity of the headache.

The presence of chronic diseases, as defined by the chronic discase score was strongly associated with the use of antidepressants within the migraine population. Of particular interest was the higher usage of NSAlDs, migraine prophylactic medications (including amitriptyline), and benzodiazepines by migraine patients initiating anridepressants as compared to those who did nor. $A$ recent study found that the use of antidepressants and benzodiazepines was predictive for the initiation of migraine prophylacric medication, which indirectly highlights the relationship between increased severiry of migraire and psvchiarric comorbidity (Rahimitoola $e f$ al. 2002: Radat $d$ al, 1999). The elevated use of benzodiazepines may best be explained by the faet that migraincurs suffering from co-existing depression are also likely to suffer from anxiery disorders whereby the use of benzodiazepines may be required (Juang ot $a$. . 2000: Birkenhacger ot a/. 1995).

A higher severity index indirectly characterised by a hean consumption ( $>150$ ) DDDs per year) and increased concomitant use of specific abortive migraine drugs was likewise found to be strongly associated with the initiation of antidepressants in our study $A$ higher prevalence of anxiety and depression has been associated with patients suffering from severe forms of migraine and chronic the of acute migraine medication (Stewart et d/. 1994: Lipton of al. 2000; Juang of al, 2000; Radat of al., 1999). Mitsikostas of al. (1999) found that the risk of depressive disorders was dramatically elevated in patienrs with drug overuse headache and may be the result of prexisting comorbidity of severe migraine and depression or vice versa. Based upon these and our findings it can be implied that the need for antidepressive treatment by our parients is strongly related to patients in whom the severiry of migraine and therapeutic demands are increased. Furthermore, these patients, particularly those suffering from migraine with aura and depression are at inereased risk for attempted suicide compared to patients with depression or migraine alone (Breslau, 1998). Our study further emphasises the importance of recognising and treating psychiatric comorbidity in migraineurs.

A major limitation to our seudy was antributed to the lack of diagnostic or clinical information. For this reason, we were unable to differentiate between migraine and cluster headache among sumatriptan patients or mignaine patients actually suffering from depression. Parients suffering from cluster headache compared to migraine patients often require increased use of abortive medications, such as sumatriptan preferably by the subcutaneous 
dosage form, due to the increased frequency of headache artacks. Therefore our claim that heavy use of specific abortive medication is an indirect estimation of increasing severity of migraine may be misleading due to the fact that the higher therapeutic intensity categories defined in this studv may have largely included patients suffering from cluster headache. However, in view that the prevalence of this syndrome in the general population is extremely low $(0.05 \%-0.2 \%)$ compared to migraine ( $10 \%-$ $15 \%$ ) and the fact that almost all heav users were tabletonly users, we believe that this potential limitation is of minor significance (Tomkins of al., 20(0)1; Tonon $f t a l$, 2002).

In order to identify migraincurs suffering from depression we were required to the specific antidepressant drugs as markers for the latter which will wirhour doubt exert a confounding effect on our analysis. Most importantly, the use of orher antidepressants, such as fluvoxamine or fluoxerine, with or withour specific anti-migraine drugs may have been a deliberate approach of the physician to treat migraine alone or both migraine and depression in certain paticnts. However, sinee these drugs were not recomnended by narional and incernational therapeuric gudelines for migraine during the study period, we did not include them as established migrane prophylactic agenrs. Furthermore, antidepressants are used for a variery of other disorders including obsessive-compulsive disorder, sleeping disorders and neuropathic pain, therefore leading to potential misclassification of depression in some patients. Since amitriptyline was recommended as a migraine prophylactic drug of choice by therapeutic guidelines for generaf practitioners in The Netherlands and elsewhere we were faced with the dilemma whether or not to include this drug in the analysis. as our estimation of the incidence of antidepressant treatment in our migraine population will eertainly have been effected. Nevertheless our estimations should be viewed with caution and the overall incidence of antidepressant treatment should be restricted to those drugs selected in our study. Finally, some imprecision in our analysis of the different usage patterns of and estimation of therapeuric intensity as a measure of specific abortive migraine drug consumption may exist as an assumption was made that a prescription presented at the pharmacy correlates with consumption of the drug. However, estimation of drug consumption need not be a problem for recipients of multiple prescriprions, since prescriptions repeated consiscently can serve as strong evidence of drug use by patients (Petri et al, 1988). Our analysis of therapeutic intensicy for example included only those patients who presented more than one prescription for ergotamine or sumatriptan during the cotal follow-up period.

In conclusion, although a slight increased use of antidepressants was found in our migraine population compared to the non-migraine population, the difference was fir lower rhan that estimated for the prevalence of depression in migraine. Despire the limitations surrounding our study, we believe this adds to existing evidence that psychiatric comorbidity is under treated in general practice for paticnts suffering from migraine. Increased efforts should be made to idencity migraineurs at heightened risk for psychiatric co-morbidity as this group probably represents that segment of the migraine popularion in whom medical and therapeuric manage ment is problematic.

\section{Acknowledgements}

This scudy is funded by a grane from the The Royal Dutch Association for the Advancement of Pharmaceutical Sciences (KNMP), The Hugue, The Netheriands and SIR Institute for Pharmacy Practice Research, Leiden, The Nerherlands.

\section{References}

Arsatomical Therapewtio Chemical \{ATC $\}$ classifcation index $\{1993\rangle$. Osio WHO Collatworiting Centre for Drigg Statistios Methodology.

Bellantubre C. Mazzi MA, Tansella M, Riro R, Goldberg D (2002). The identification of depression and the coverager of antidepressiant ctuge

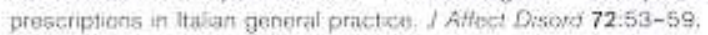

Birkenhaeger T. Moleman P, Nolen W (1995). Benzodiazepmes tor degreessco? A resiew of the literatife for Clan Psichochamacol 10-18t-195

Breelau N. Schultz LR, Stewart WF Lipion RB, Lucia VC, Welch KM $\{2000\}$ Headache and major depression: is the association specific to migraine? Rewroingy 54.30日-313.

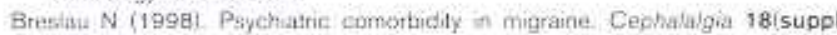
22:56-61

Breslau N, Davis GC Andreski P \{1991\}, Migraine psychiatnc discorders and suicide attemots: an epidemiologic study of young adults. Psychiatry Res $41: T 1-23$

Devien $J$ (1994), Anxiety and depression in migraine J R Soc Med 87:338-341. Druss BG, Holl RA, Rosenheck RA (2000). Under use of antideoressants in mapot ciepresson: prevalence and correlates in a national sample of young adults. I Clin Psychiatry 61:234-237.

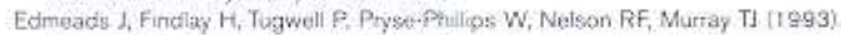
Impact of migraine and tonson-type headacho on life-style, cursulting behaviour, and medication use a Canadan population survoy. Can / Neunos Soi $20: 131-137$

Evers S, Gralow I. Baner B. Suht B. Buchheister A, Husstedt IW. et al, (1999). Sumatriptan and ergatamine overuse and drug induced headache- nn chincoepicentolocic study. Clin Neuropharm 22:201-206.

Fasmer $\mathrm{OB}$ (2001). The prevalence of mgraine in patients: with bipclar and unipdar atlective disorders. Cephaiaiga 21:894-日99.

Futiong S. Pryse-Phillips W. Crowley M. Tumer C (1996). Prescritong practices for the management of headache in Newtoundland and Labeador. Henctoctie $36: 542 \div 546$

Gaist D (1999). Use and overuse of sumatnotan; Phamacoepidemiological studies based on prescription register and interview data. Cephalagia $19,735-761$.

Guiliemo E, Pehissoip A, Lepme AP (1999). Mental disorders and migrane opidomiologit studics. Enctephate $25.436-442$.

Herings RM, Bakker A, Stricker BH, Nap G (1992). Phamaco-morbidity linkage: a leasbility study comparing morbidity in two phammcy based exposate cohor1s: 3 Eoidemioi Community Heath $46: 136-140$

Jaffe RT, Sokolov ST \{1997). Coradministration of fluoxetine and sumathptan: the Canedian expernence. Acta Psychiaty Soand 95:551-552.

Juish WV. Cudy P, Bennet D. Harris R (2000). An epidemiological case control stucty of mignaine and its associated comorbid canditons. Ann Epidemioi $10 ; 460$

Jueng KD. Warg SJ. Fuh JL Lu SR, Su TP 12000 . Comorty dity of depressive and anxiety disorders in chronic daly headacto and its subtypes. Heaudache 40:818-823.

Korf won M. Wagner EH, Saunders K (1992) A chromic diseage store lrem automated phamacy data. / Chin Epioiemiol 45:197-203. 
Lipton RB, Hamelsky SW, Kalodner KB, Steiner T], Stewart WF (2000), Mograine, quality of lifo, and depression: a population based case-control study. Neurology 55:629-635.

Mattsson P. Ekselius L $\{2002\}$. Migraine, major depression, panic disorcef, and personality traits in women aged $40-74$ yeats: a population-based study Cephalagia 22:543-551.

Merikangas KR, Angst J, Fler H (1990). Migraine and psychopathology. Regxats of the Zurich cohor: stedy of young adulte. Arch Gen Psychiatry 41 649-853.

Millsan D. Fischer M, Croft P, Goadsby Pf (2000). Are triptans with untanced lipophilicity used for the acute treatment of migrume associated with an increased consulting rate for depcessive illness? Cepholaigia 20;732 -737.

Mitsikostas DD. Thomas AM (1999). Comorbidity at headache and depressivet disordars Cephatigia 19:211-217

Peroutka SJ, Price SC. Wilhoit. Jornes KW (1998), Comorbid migrane with auta anxicty, and depression is associated with dopanine D2 receptor Neol alletes. Mol Med 4:14-21.

Petri $H$, de Vet CW. Naus I, et al f1988). Pregcription sequence analysis a new and tast method for assessing certain actverse reactions of prescription drugs in large populations. Stat Med 7.1171-1175.

Putnam GP, OQuinn S, Bolden Watsen CP. Dsvis RL, Gutterman DL. Fox AW (1999). Migraine polypharmacy and the tolerability of sumatnptani a largescale, prospective study, Cephiala!g:a 19:668-675

Radat F, Sakh D, Lute G, el Amrani M. Ferren M, Bousser MG \{1 999j. Psychiatric comorbidity as related to heacache inducod by chronic substance use in migraineuss. Headache 39:477-480.
Rahimtoola $H$, Buuma $H_{1}$ Tigssen CC; Leutkens HG, Egberts ACG (2002) Incidence and detetrminants of migraine prophylactic medication in The Netherlands. Eur J Clin Pharmacol 58:149-155.

Rahimtocla H, Buarma H. Tijsen CC, Leufkens: HG, Egberts ACG (2003) Single use of sumatriptan-a patient interview study. Headache 43 : $109-116$

Rouilon E, Blachier C, Dreylus IP, Bcuhassias M, Allicar MP \{1996\}. Pharmaco epidemiologic atudy of antidepressast drugs in the generat population. Encephaio 1:39-48

Siberstein SD, Goadsby PJ (2002). Migrane: preventive treatrinent. Ccohalaigua $22: 491-512$

Stewart W, Breslau N, Kock PE (1994), Comortidity of migrame and pance disctder. Netrolozy 44 suppl 7):23-27.

Swartz K. Pratt L. Haroutune K, Ching L, Eaton W (2000). Montal disorders and two incidence of migraine headaches in a community sample. Arch Gon Psych 157:1-17.

Tomkins GE, Jackson JL. O'Wailloy PG, Baiden E, Santoro JE (2001). Treatment of chronic headache with antidepressants: a meta-analysis. Am J Med
$111: 54-63$

Tonon C, Guttmann S. Volpini M, Naccarato S, Cottelli P, D'Alessandro R (2002). Prevalence and incudence of cluster headache in the Republic of San Marino. Neisrology 58:1407-1409.

von Kortf M, Black L.K, Saunders K, Galer BS (1999). Headwche medicatron use among primary care headache patients in a health maintenance organization. Cephaialgu 19:575-580. 